\title{
Cardiovascular System Mortalities in Nigeria; Case Study of the University of Port Harcourt Teaching Hospital
}

\author{
Christopher Chinedu Obiorah \\ Department of Anatomical Pathology, University of Port Harcourt Teaching Hospital, Port Harcourt, Nigeria \\ Email: christopher.obiorah@uniport.edu.ng
}

How to cite this paper: Obiorah, C.C. (2019) Cardiovascular System Mortalities in Nigeria; Case Study of the University of Port Harcourt Teaching Hospital. World Journal of Cardiovascular Diseases, 9, 867-878. https://doi.org/10.4236/wjcd.2019.912077

Received: October 19, 2019

Accepted: December 3, 2019

Published: December 6, 2019

Copyright $\odot 2019$ by author(s) and Scientific Research Publishing Inc. This work is licensed under the Creative Commons Attribution International License (CC BY 4.0).

http://creativecommons.org/licenses/by/4.0/

\begin{abstract}
Background: Studies have suggested epidemiological transition in the mortality pattern in Nigeria from communicable to non-communicable diseases of which Diseases of the cardiovascular system (DCVS) is prime. DCVS is thus a growing public health concern but its mortality profile is under-studied in Port Harcourt. This study was therefore designed to review the mortality profile of DCVS in Port Harcourt. Methodology: A retrospective case controlled study of deaths ascribed to DCVS at the University of Port Harcourt Teaching Hospital (UPTH) between January 2012 and December 2017. The composite diseases were grouped using the ICD10 scheme and analyzed using SPSS version 23. Minitab version 16 was used for trend analysis. Results: Of the overall 1902 deaths recorded within the period, 566 (29.8\%) were cardiovascular system related. Of these, 301 (53.3\%) were males and $265(46.7 \%)$ were females. The elderly of 50 - 99 years were most commonly affected (65.5\% of the mortalities). Cerebrovascular accidents (CVA) accounted for 322 deaths (56.9\%); various types of shock caused 116 deaths (20.5\%) while congestive cardiac failure (CCF) accounted for 114 deaths (20.1\%). Pulmonary embolism, myocardial infarction, carotid aneurysm, and hypertensive encephalopathy caused $1.8 \%, 0.4 \%, 0.2 \%$, and $0.2 \%$ deaths respectively. Peak annual mortality of 143 (25.3\%) was recorded in 2013. Although the trend of mortality was undulating, there was an overall increase in annual incidence over the years. Conclusion: DCVS constitute the commonest systemic cause of death in Port Harcourt. Governmental and donor agencies involved in public health policy planning and implementation should scale-up strategies for the prevention and control of DCVS in order to stem the rising tide of associated mortalities.
\end{abstract}

\section{Keywords}

Mortality, Diseases, Cardiovascular System, Stroke, Port Harcourt, Nigeria 


\section{Introduction}

Diseases of the cardiovascular system (DCVS) constitute enormous public health challenges [1] and contribute significantly to the burden of non-communicable diseases in sub-Saharan Africa [2]. WHO has reported that 17.9 million (31\%) deaths are annually recorded globally from DCVS [3]. About $75 \%$ of these deaths occur in low and middle-income countries [4]. Although diseases of the cardiovascular system was reported as the second commonest cause of death after infectious diseases in Africa, current projections hold that an increase of $20 \%$ is expected by 2020 and the greatest burden likely to be experienced in enormous public Africa [5] [6] [7]. Consistent with this notion, other reports have stated that in most developing countries including Nigeria, deaths from non-communicable diseases like DCVS and cancers are on the rise while communicable diseases like infectious diseases are on the decline [8] [9] [10].

In Sub-Saharan Africa generally, including Nigeria, the current rise in DCVS is attributable to some modifiable risk factors, including rapid urbanization, effects of globalization and poverty especially among residents of urban areas [11] [12]. Also, the resultant preference for energy-dense and processed foods in lieu of traditional diets of natural composition, devoid of additives and colorants is a risk factor for the development of DCVS [13]. Other primary risk factors causing cardiovascular system-related deaths include; hypertension, diabetes, alcohol abuse, tobacco abuse, obesity and lack of physical exercise [14] [15]. Mortality due to DCVS significantly increases socio-economic costs, loss of productivity, disability and remains a contributing factor to health inequalities and poverty in developing countries [14].

The specific causes of mortalities associated with DCVS show significant global variation. For instance, among the developed countries, coronary-artery diseases remain the main cause of death while in sub-Saharan Africa, stroke is the leading cause of death followed by hypertensive heart diseases and heart failure [16]. Previous hospital-based studies identified hypertension as the commonest cause of cardiovascular mortality in Nigeria [17].

As the people of Nigeria gradually goes through epidemiologic transition with increasing burden of non-communicable diseases like DCVS, Port Harcourt, with cosmopolitan settlement sequel to decades of oil and gas activities that attract people of multiple races, nationalities, and tribes deserves an evaluation of the profile of cardiovascular system mortality.

The objective of this study is to determine the trend and causes of deaths due to diseases of the cardiovascular system at the University of Port Harcourt Teaching Hospital.

\section{Methodology}

This six-year retrospective case-controlled study was carried out at the University of Port Harcourt Teaching Hospital (UPTH), Port Harcourt, Nigeria. UPTH with a bed capacity of 882 , is the foremost tertiary health institution in Rivers 
state serving as the major referral center for residents of the State. It also serves some residents from the neighboring states of Bayelsa, Abia, Imo, and Akwa Ibom-all in the oil-rich Niger Delta region of Nigeria [18]. In all, UPTH serves a population of not less than 10 million. Death registers, available case notes and death certificates of those who were managed for DCVS between January 2012 and December 2017 were selected and further reviewed. Information on: age, sex, clinical diagnosis that warranted admission, secondary causes of deaths were eluted. The causes of death were classified using the ICD 10 scheme. IBM Statistical Package for Social Sciences (SPSS) version 23 (SPSS Inc., Chicago, IL, USA) was utilized in the data analysis. Proportions and percentages were used to summarize qualitative data while means, median, and standard deviation for quantitative data. Student's t-test and Mann-Whitney U-test, for skewed data, were used to test the significance of differences between different mean and median values, respectively. The significance of association for qualitative variables was investigated by the Chi-square test. P-value of $<0.05$ at $95 \%$ confidence interval (CI) was considered significant. Forecasting of the future trend was done with Minitab, version 16. The University of Port Harcourt Teaching Hospital (UPTH) Ethics Committee granted approval for this study (UPTH/ADM/90/ S.II/VOL.XI/859).

\section{Results}

Mortalities from DCVS constituted 566 (29.8\%) of the overall 1902 mortalities recorded within the study period. There was a slight predominance of males301 cases $(53.3 \%)$ over females with 265 cases $(46.7 \%)$. Peak mortality for males and females was observed in 2013 (Figure 1). The incidence increased with age till the bimodal peak ages in the $6^{\text {th }}$ and $7^{\text {th }}$ decades with the occurrence of 120 cases $(21.2 \%)$ and 119 cases $(21.0 \%)$ respectively (Table 1 ). The annual mean ages range from 50.9 to 58.4 years with an overall mean age of $54.5 \pm 18.09$ years (Table 2). The average of the median ages was 56 years while the annual range was 49 - 61 years. The mean age for female decedents was $53.2 \pm 19.1$ while for the males it was $56.0 \pm 17.1$. For young adults aged 20 - 39 years, DCVS predominated among the females while for those aged above 40 years, there was a predominance of DCVS among the males (Table 1). While CVA and cardiac failure were noted more among the males, (244 vs. 192), shock of various types and pulmonary embolism were noted more among females (70 vs. 56). The trend was undulating with a peak occurrence in 2013 and least in 2012 (Figure 2). Cerebrovascular accident was the most common cause of DCVS with 322 cases (56.9\%) followed by shock of all types and congestive cardiac failure with 116 cases $(20.5 \%)$ and 114 cases $(20.1 \%)$ respectively (Table 3$)$. The primary causes of mortality among children (0 - 19 years) are depicted in Figure 3 below. For CVA, the peak age of occurrence was 60 - 69 years with $76 / 322$ cases $(23.6 \%)$ while for the shock of all types there were bimodal peaks occurring at $60-69$ and 30 - 39 years with $24 / 116$ cases (20.7\%) and 23/116 cases (19.8\%) respectively. 
Mortality from CCF peaked at 50 - 59 years with 31/114 cases (27.2\%) (Table 4). Forecast analysis (2012-2020) showed a steady increase in mortality from 20182020 (Figure 4).

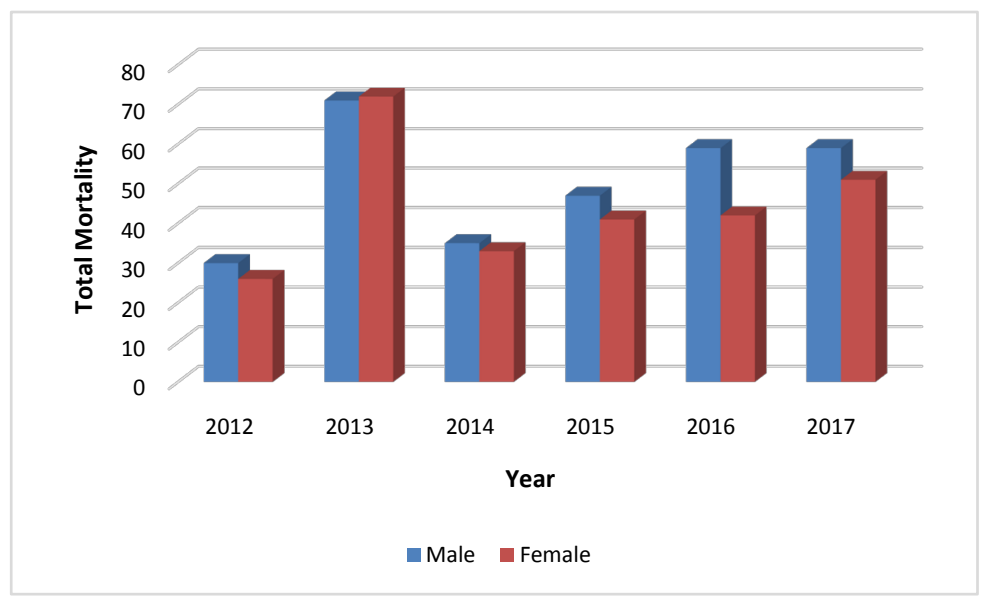

Figure 1. Annual gender disparity of mortality from DCVS.

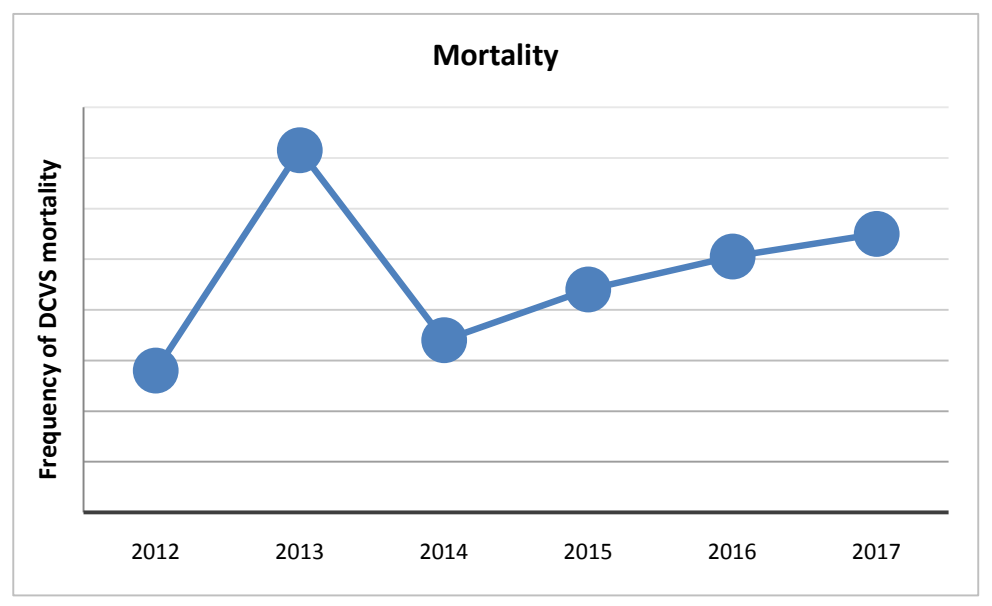

Figure 2. Mortality Trend of DCVS in UPTH, 2012 to 2017.

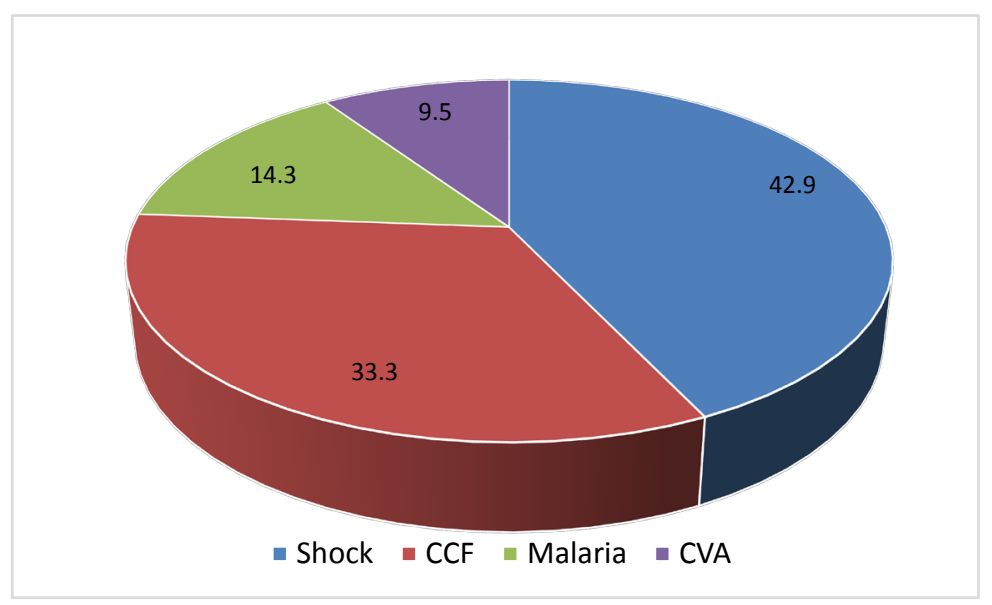

Figure 3. Causes of death due to DCVS in children aged 0 - 19 years. 


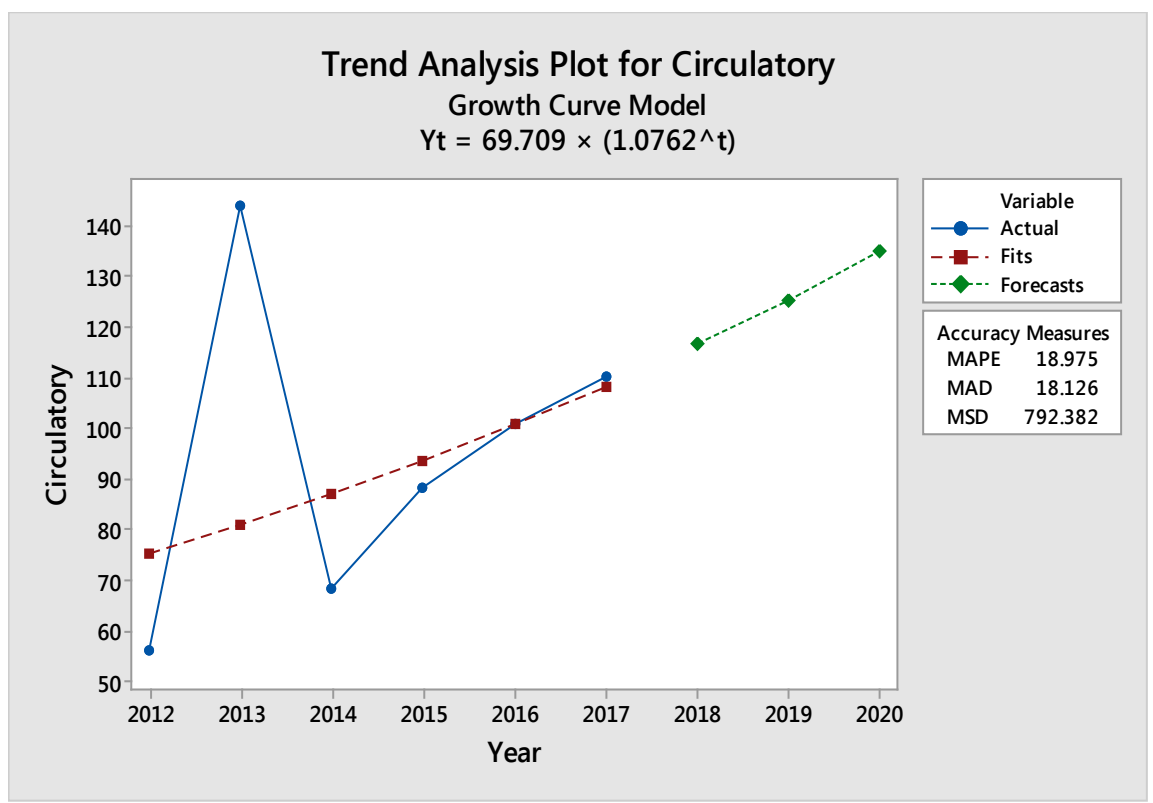

Figure 4. Trend and projection analysis of DCVS in UPTH (2012-2020).

Table 1. Age and sex distribution of cardiovascular mortality (2012-2017).

\begin{tabular}{ccccc}
\hline \multirow{2}{*}{ S/N } & Age Range & \multicolumn{2}{c}{ DCVS } & Total \\
\cline { 3 - 4 } & $($ Yrs $)$ & Male & Female & \\
\cline { 3 - 4 } 1 & $0-9$ & $8(2.7)$ & $6(2.3)$ & $14(2.5)$ \\
2 & $10-19$ & $4(1.3)$ & $3(1.1)$ & $7(1.2)$ \\
3 & $20-29$ & $5(1.7)$ & $20(7.5)$ & $25(4.4)$ \\
4 & $30-39$ & $20(6.6)$ & $46(17.4)$ & $66(11.7)$ \\
5 & $40-49$ & $58(19.3)$ & $25(9.4)$ & $83(14.7)$ \\
6 & $50-59$ & $69(22.9)$ & $51(19.2)$ & $120(21.2)$ \\
7 & $60-69$ & $64(21.3)$ & $55(20.8)$ & $119(21.0)$ \\
8 & $70-79$ & $56(18.6)$ & $36(13.6)$ & $92(16.3)$ \\
9 & $80-89$ & $13(4.3)$ & $20(7.5)$ & $33(5.8)$ \\
10 & $90-99$ & $4(1.3)$ & $3(1.1)$ & $7(1.2)$ \\
TOTAL & & $301(53.3)$ & $265(46.7)$ & $566(100)$ \\
\hline
\end{tabular}

NB: Values in parenthesis are for percentages. Number of Disease of cardiovascular system $(n)=566$.

Table 2. Yearly distribution of mean age.

\begin{tabular}{ccccccc}
\hline Age Dependent Variables & $\mathbf{2 0 1 2}$ & $\mathbf{2 0 1 3}$ & $\mathbf{2 0 1 4}$ & $\mathbf{2 0 1 5}$ & $\mathbf{2 0 1 6}$ & $\mathbf{2 0 1 7}$ \\
\hline Mean & 50.911 & 53.909 & 56.309 & 54.398 & 53.149 & 58.400 \\
Std. Error of Mean & 2.5167 & 1.5627 & 2.3734 & 1.7470 & 1.7304 & 1.6826 \\
Median Age & 49.000 & 55.000 & 60.500 & 56.000 & 55.000 & 61.000 \\
Std. Deviation & 18.8335 & 18.6875 & 19.5717 & 16.3879 & 17.3899 & 17.6475 \\
\hline
\end{tabular}


Table 3. Gender distribution of mortality from DCVS.

\begin{tabular}{|c|c|c|c|c|c|c|}
\hline \multirow{2}{*}{ Cause of Death } & \multicolumn{4}{|c|}{ Gender } & \multicolumn{2}{|c|}{ TOTAL } \\
\hline & $\mathrm{F}$ & $\%$ & $\mathbf{M}$ & $\%$ & Frequency & $\%$ \\
\hline Cerebrovascular Accidents & 144 & 25.4 & 178 & 31.4 & 322 & 56.9 \\
\hline Shock of varying types & 63 & 11.1 & 53 & 9.4 & 116 & 20.5 \\
\hline Congestive Cardiac Failure & 48 & 8.5 & 66 & 11.7 & 114 & 20.1 \\
\hline Pulmonary Embolism & 7 & 1.2 & 3 & 0.5 & 10 & 1.8 \\
\hline Myocardial Infarction & 2 & 0.4 & 0 & 0 & 2 & 0.4 \\
\hline Carotid Aneurysm & 1 & 0.2 & 0 & 0 & 1 & 0.2 \\
\hline Encephalopathy & 0 & 0 & 1 & 0.2 & 1 & 0.2 \\
\hline Total & 265 & 46.8 & 301 & 53.2 & 566 & 100.0 \\
\hline
\end{tabular}

F: Female. M: Male.

Table 4. Age distribution of DCVS causes.

\begin{tabular}{|c|c|c|c|c|c|c|c|c|c|}
\hline \multirow[b]{2}{*}{ Age group } & \multicolumn{7}{|c|}{ Cause of death } & \multicolumn{2}{|c|}{ Total } \\
\hline & $\begin{array}{c}\text { Carotid } \\
\text { aneurysm }\end{array}$ & CCF & CVA & Encephalopathy & $\begin{array}{l}\text { Myocardial } \\
\text { infarction }\end{array}$ & $\begin{array}{c}\text { Pulmonary } \\
\text { embolism }\end{array}$ & Shock & Frequency & Percentage \\
\hline $0-9$ yrs & 0 & 5 & 1 & 0 & 0 & 0 & 8 & 14 & 2.4 \\
\hline $10-19$ yrs & 0 & 2 & 1 & 0 & 0 & 0 & 4 & 7 & 1.2 \\
\hline $20-29$ yrs & 0 & 4 & 7 & 0 & 0 & 1 & 13 & 25 & 4.4 \\
\hline $30-39$ yrs & 0 & 14 & 28 & 0 & 0 & 1 & 23 & 66 & 11.6 \\
\hline $40-49$ yrs & 0 & 17 & 48 & 1 & 0 & 2 & 15 & 83 & 14.7 \\
\hline $50-59$ yrs & 0 & 31 & 72 & 0 & 0 & 2 & 15 & 120 & 21.2 \\
\hline $60-69$ yrs & 0 & 16 & 76 & 0 & 1 & 2 & 24 & 119 & 21.2 \\
\hline $70-79$ yrs & 0 & 17 & 64 & 0 & 1 & 0 & 10 & 92 & 16.3 \\
\hline $80-89$ yrs & 1 & 6 & 21 & 0 & 0 & 2 & 3 & 33 & 5.8 \\
\hline 90 - 99 yrs & 0 & 2 & 4 & 0 & 0 & 0 & 1 & 7 & 1.2 \\
\hline TOTAL & 1 & 114 & 322 & 1 & 2 & 10 & 116 & 566 & 100 \\
\hline
\end{tabular}

N/B: CCF: Congestive Cardiac Failure. CVA: Cardiovascular accident.

\section{Discussion}

Mortality data serve as an important indicator of the health status of a people and constitutes an indispensable factor in public health programming and planning. It assists policymakers to focus on key areas of intervention [19]. The mortality pattern of DCVS in UPTH presented in this study is important considering the cosmopolitan settlement in Port Harcourt as a result of the active oil and gas activities going on in the Niger Delta region of which Port Harcourt is the epicenter; with the attendant cosmopolitan settlement and influx of people of all races and many nations. This study presents the facts and figures of cardiovascular system mortalities in Port Harcourt and adds to the growing literature on the rising incidence of cardiovascular system-related morbidity and mortality 
documented in other centres across Nigeria. Although this study was based on clinical diagnoses derived in turn from patient clerking, physical examination findings as well as laboratory and radiology investigation outcomes, it is handy considering the general negative attitude of the people of our environment to voluntary hospital autopsies. It thus fills the gap in providing good hospital data for mortalities from DCVS.

A total of 566/1902 (28.9\%) deaths were recorded from DCVS. This makes it the commonest systemic cause of death in UPTH. This is well above the $11 \%$ mortality ascribed to cardiovascular diseases by WHO for Nigeria [10]. Other local studies have also alluded to the high prevalence of DCVS. For example, Obiorah and Amachree in their systemic analysis of sudden natural deaths at the Brathwaite Memorial Specialist Hospital (BMSH) Port Harcourt, reported that diseases of the cardiovascular system accounted for $87.6 \%$ of the sudden natural deaths autopsied [20]. In another 3-year retrospective review of mortality in women of reproductive age in UPTH, hypertensive disorders in pregnancy accounted for $41.3 \%$ of the deaths [21]. Besides, other similar studies carried out in Umuahia South Eastern Nigeria [22] and Ile-Ife South Western, Nigeria [23] also reported that DCVS were the commonest systemic causes of deaths in the respective tertiary hospital centres. Elsewhere in Tanzania, the recorded mortality due to diseases of the cardiovascular system was $6.31 \%$ of the total mortality [24] which is low compared to our findings and other previous Nigerian studies. Our high rate is only comparable to reports in the United States of America, where diseases of the cardiovascular system was reported as the leading cause of death [25]. This represents an epidemiologic shift as decades ago; the most feared cause of death in Nigeria was infectious diseases, with hundreds of thousands of people losing their lives to it in its varying modes and appearances. Our study shows that this is not anymore! DCVS are the new nightmare, spreading subtly but consistently into many homes, leaving tears, sorrows, and deaths across Rivers state. This is consistent with global trends where DCVS remains the leading cause of death [26]. In 2015 it accounted for about 1.91 million (36.7\%) deaths in the 28 European Union countries [27]. In Sub Saharan African countries, the burden of deaths from DCVS has also steadily risen as further alluded to by this study finding [28]. The rising incidence of DCVS suggests imminent epidemics of cardiovascular diseases in Nigeria. In fact, what we as a nation should anticipate and plan for may not differ from what was reported in the United States where 2 to 3 decades ago, African Americans who had lower cardiovascular disease rates later and currently has overtaken North Americans in recording higher incidence of cardiovascular diseases, which was strongly attributed to modifiable lifestyles and extended exposure to risk factors [29] [30] [31]. Urbanization and globalization have exposed Nigerians to the same lifestyles and risk factors which include: predominant consumption of westernized diets, sedentary lifestyles, increasing obesity and smoking. Therefore instituting urgent measures that will stem the rising tide is urgently required. The measures should include: 
embarking on public awareness and advocacy programs on lifestyle changes and other prevention strategies, training of personnel on screening exercises, correct and timely diagnoses of cases, and provision of necessary treatment infrastructure and subsidized drugs.

We recorded $46.8 \%$ of deaths among females and $53.2 \%$ among males. This gender distribution compares favorably with similar Nigerian studies which reported slight predominance of males in mortalities caused by DCVS-[17] [32] [33] [34]. Factors such as age, hypertension, total cholesterol, and low-density lipoprotein have a greater effect on men thereby predisposing them to more cardiovascular risks [35]. Women have also been reported to have better control of hypertension than men thereby reducing the risk of mortality from DCVS [36] [37]. Another explanation to the higher DCVS mortality in males in our study stems from their predisposition to other common risk factors such as smoking, heavy drinking, poor dietary habit [38] and diabetes [39]. We also add that the state of Nigeria's economy and the associated pervading poverty tends to keep the majority of men on their toes, attempting to make ends meet for their families where they are breadwinners. This predisposes them to psychological and emotional stress and frustration, especially for those who are unable to meet up to the expected family and societal demands. In line with our thought, Steyn et al. in their interheart African study identified smoking and permanent stress as the strongest risk factors of cardiovascular diseases among Africans [31]. However, for younger decedents 20 - 39 years, mortality was noted more among females. The reasons for this twist in the gender trend are not clear but may be related to the general prevalence of obesity which is a strong risk factor for cardiovascular diseases among females in Nigeria [40].

The proportion of recorded deaths among children and adolescents aged 0 19 years was $4 \%$. This is higher than $0.7 \%$ mortality from DCVS reported among children of the same age range in hospital-based study in south Eastern Nigeria by Arodiwe et al. [41]. The commonest causes of DCVS mortality in our study was the shock of various types (42.9\%) and CCF (33.3\%) (Figure 3). This further goes to show that it could be as a result of diarrhoeal diseases and other infective conditions that could end in septic shock. The heart failures could be associated with anaemia often resulting from several illnesses encountered in children commonest of which is malaria.

The overall mean age was 54.5 years which is similar to the 54.9 years reported in Ibadan by Adedapo et al. [32] The people of the mean age group constitute the bulk of experienced workforce and captains of businesses. Therefore their demise definitely impacts negatively on the economy and creates vacuum in families with attendant multiplier effects on the already bad societal poverty. A study by the American heart association put the indirect costs of lost earnings and household productivity from premature death due to cardiovascular system diseases at 237 billion dollars [42].

Different Nigerian studies have shown inconsistent reports on the order of 
occurrence among the specific causes of deaths from DCVS. The order of our study is: Cerebrovascular accidents $>$ shock $>$ congestive cardiac failure $>$ Pulmonary embolism $>$ myocardial infarction $>$ carotid aneurysm $>$ encephalopathy. That of Lagos (South Western Nigeria) was: hypertensive heart diseases $>$ cerebrovascular accident $>$ myocardial infarction $>$ heart failure $>$ cardiomyopathies $>$ atherosclerosis $>$ pulmonary embolism [17], while Umuahia (SouthEastern Nigeria) was: cerebrovascular accident $>$ congestive cardiac failure $>$ hypertension/hypertensive heart disease $>$ shock $>$ subarachnoid hemorrhage $>$ acute pulmonary edema and cor pulmonale [43]. In Kano (North-Western Nigeria), the order was: hypertension $>$ stroke $>$ heart failure $>$ rheumatic heart disease $>$ congenital heart disease [6]. The plausible reason for this inconsistency is not clear and may underlie environmental influence on disease patterns and prevalence. Government through the management of UPTH should make adequate provision for proper management of cerebrovascular accidents that will ensure better treatment outcomes. Specifically, screening for hypertension and diabetes which are common causes of CVA and heart failure in later stages should be made a routine. On the contrary, myocardial infarction was very uncommon in this study. While this is in line with Nwanelis' submission in his review study on Coronary Heart Disease in Nigeria that CHD is relatively uncommon in $\mathrm{Ni}$ geria and therefore does not contribute significantly to morbidity and mortality from cardiovascular diseases but also call to question the diagnostic capacity of most facilities in Nigeria for both acute and chronic CHD [44]. It is possible that the disorder is under-diagnosed and therefore under-reported.

The trend was undulating with a peak occurrence in 2013 and least in 2012. Short of the spike in 2013, the course and trend showed a steady upward swing. This is similar to reports from other centres across Nigeria that indicate a rising incidence of DCVS.

This study was limited by the non-autopsy confirmation of the causes of death and dependence on clinical diagnoses based data only. The general poor recordkeeping attitude of the hospital has not helped the situation either as it is possible that some cases were missed out.

\section{Conclusion}

This study shows an epidemiologic shift from infectious causes to DCVS as the commonest causes of mortality for admitted patients in UPTH Port Harcourt. The demise of people of the mean age of 54 years owing to DCVS impacts negatively on the economy and creates a vacuum in families with attendant multiplier effects on the already bad societal poverty. There is, therefore, a need to aggressively develop and implement health programs and interventions that can help reduce risk factors especially for cerebrovascular accidents, which was the most common cause of DCVS mortality observed; while enhancing the documentation of mortalities resulting from these diseases for tracking of the effectiveness of instituted intervention measures. 


\section{Acknowledgements}

I acknowledge the supervising matrons of the various wards and emergency units for giving us access to the records of the wards and units. Mr. Sorbari Igbiri is appreciated for his technical support in this work.

\section{Conflicts of Interest}

The author declares no conflicts of interest regarding the publication of this paper.

\section{References}

[1] Kumar, S. (2017) Cardiovascular Disease and Its Determinants: Public Health Issue. Journal of Clinical Medicine and Therapeutics, 2, 1.

[2] Gaziano, T., Reddy, K.S., Paccaud, F., Horton, S. and Chaturvedi, V. (2006) Cardiovascular Disease. In: Jamison, D., Breman, J.G., Measham, A.R., Alleyne, G., Claeson, M., Evans, D.B., et al., Eds., Disease Control Priorities in Developing Countries, 2nd Edition, World Bank, Washington DC.

[3] WHO. (2019) Cardiovascular Diseases (CVDs). https://www.who.int/news-room/fact-sheets/detail/cardiovascular-diseases-(cvds)

[4] Nag, T. and Ghosh, A. (2013) Cardiovascular Disease Risk Factors in Asian Indian Population: A Systematic Review. Journal of Cardiovascular Disease Research, 4, 222-228. https://doi.org/10.1016/j.jcdr.2014.01.004

[5] Mbewu, A. (2009) The Burden of Cardiovascular Disease in Sub-Saharan Africa: Burden of Cardiovascular Disease. SA Heart, 6, 4-10. https://doi.org/10.24170/6-1-2005

[6] Mukadas, A.O. and Misbau, U. (2009) Incidence and Patterns of Cardiovascular Disease in North Western Nigeria. Nigerian Medical Journal, 50, 55.

[7] Alwan, A. (2011) Global Status Report on Noncommunicable Diseases 2010. World Health Organization.

[8] Sen, K. and Bonita, R. (2000) Global Health Status: Two Steps forward, One Step Back. The Lancet, 356, 577-582. https://doi.org/10.1016/S0140-6736(00)02590-3

[9] Yusuf, S., Reddy, S., Ôunpuu, S. and Anand, S. (2001) Global Burden of Cardiovascular Diseases: Part I: General Considerations, the Epidemiologic Transition, Risk Factors, and Impact of Urbanization. Circulation, 104, 2746-2753. https://doi.org/10.1161/hc4601.099487

[10] WHO. (2017) Nigeria. World Health Organization, Regional Office for Africa.

[11] Boateng, D., Wekesah, F., Browne, J.L., Agyemang, C., Agyei-Baffour, P., de-Graft Aikins, A., et al. (2017) Knowledge and Awareness of and Perception towards Cardiovascular Disease Risk in Sub-Saharan Africa: A Systematic Review. PLoS ONE, 12, e0189264. https://doi.org/10.1371/journal.pone.0189264

[12] Popkin, B.M., Adair, L.S. and Ng, S.W. (2012) Global Nutrition Transition and the Pandemic of Obesity in Developing Countries. Nutrition Reviews, 70, 3-21. https://doi.org/10.1111/j.1753-4887.2011.00456.x

[13] Curbing, N. (2015) Noncommunicable Diseases in Africa: Youth Are Key to Curbing the Epidemic and Achieving Sustainable Development. Population Reference Bureau, Washington.

[14] Cappuccio, F.P. and Miller, M.A. (2016) Cardiovascular Disease and Hypertension in Sub-Saharan Africa: Burden, Risk and Interventions. Internal and Emergency 
Medicine, 11, 299-305. https://doi.org/10.1007/s11739-016-1423-9

[15] Gersh, B.J., Sliwa, K., Mayosi, B.M. and Yusuf, S. (2010) Novel Therapeutic Concepts: The Epidemic of Cardiovascular Disease in the Developing World: Global Implications. European Heart Journal, 31, 642-648.

https://doi.org/10.1093/eurheartj/ehq030

[16] Moran, A., Forouzanfar, M., Chugh, S., Feign, V. and Mensah, G. (2013) The Epidemiology of Cardiovascular Diseases in Sub-Saharan Africa: The Global Burden of Diseases, Injuries and Risk Factors 2010 Study. Progress in Cardiovascular Diseases, 56, 234-239. https://doi.org/10.1016/j.pcad.2013.09.019

[17] Adegoke, O., Awolola, N.A. and Ajuluchukwu, J.N. (2018) Prevalence and Pattern of Cardiovascular-Related Causes of Out-Of-Hospital Deaths in Lagos, Nigeria. African Health Sciences, 18, 942-949. https://doi.org/10.4314/ahs.v18i4.13

[18] Onwuchekwa, A.C. and Chinenye, S. (2010) Clinical Profile of Hypertension at a University Teaching Hospital in Nigeria. Vascular Health and Risk Management, 6, 511-516. https://doi.org/10.2147/VHRM.S10245

[19] Frentzel-Beyme, R., Keil, U., Pflanz, M., Struba, R. and Wagner, G. (1980) Mortality Data and Statistics, Importance for Health Services and Epidemiological Research (Author's Translation). MMW, Munchener Medizinische Wochenschrift, 122, 901-906.

[20] Obiorah, C.C. and Amakiri, C.N.T. (2012) Systemic Analysis of Sudden Natural Deaths at Braithwaite Memorial Specialist Hospital Port Harcourt, Nigeria. Nigerian Health Journal, 12, 47-51.

[21] Orazulike, N.C., Alegbeleye, J.O., Obiorah, C.C., Nyengidiki, T.K. and Uzoigwe, S.A. (2017) A 3-Year Retrospective Review of Mortality in Women of Reproductive Age in a Tertiary Health Facility in Port Harcourt, Nigeria. International Journal of Women's Health, 2017, 769-775. https://doi.org/10.2147/IJWH.S138052

[22] Charles, C.N.C., Azodo, M.N.M. and Chuku, C.A. (2014) Causes and Pattern of Death in a Tertiary Hospital in lifestyles Nigeria. Sahel Medical Journal, 17, 102. https://doi.org/10.4103/1118-8561.140292

[23] Adeolu, A., Arowolo, O., Alatise, O., Osasan, S., Bisiriyu, L., Omoniyi, E., et al. (2010) Pattern of Death in a Nigerian Teaching Hospital; 3-Decade Analysis. African Health Sciences, 10, 266-272.

[24] Mboera, L.E.G., Rumisha, S.F., Lyimo, E.P., Chiduo, M.G., Mangu, C.D., Mremi, I.R., et al. (2018) Cause-Specific Mortality Patterns among Hospital Deaths in Tanzania, 2006-2015. PLoS ONE, 13, e0205833. https://doi.org/10.1371/journal.pone.0205833

[25] Pagidipati, N.J. and Gaziano, T.A. (2013) Estimating Deaths from Cardiovascular Disease: A Review of Global Methodologies of Mortality Measurement. Circulation, 127, 749-756. https://doi.org/10.1161/CIRCULATIONAHA.112.128413

[26] Moran, A., Forouzanfar, M., Sampson, U., Chugh, S., Feigin, V. and Mensah, G. (2013) The Epidemiology of Cardiovascular Diseases in Sub-Saharan Africa: The Global Burden of Diseases, Injuries and Risk Factors 2010 Study. Progress in Cardiovascular Diseases, 56, 234-239. https://doi.org/10.1016/j.pcad.2013.09.019

[27] Eurostat (2018) Cardiovascular Diseases Statistics-Statistics Explained.

[28] Roth, G.A., Huffman, M.D., Moran, A.E., Feigin, V., Mensah, G.A., Naghavi, M., et al. (2015) Global and Regional Patterns in Cardiovascular Mortality from 1990 to 2013. Circulation, 132, 1667-1678. https://doi.org/10.1161/CIRCULATIONAHA.114.008720

[29] BeLue, R., Okoror, T.A., Iwelunmor, J., Taylor, K.D., Degboe, A.N., Agyemang, C., et al. (2009) An Overview of Cardiovascular Risk Factor Burden in Sub-Saharan 
African Countries: A Socio-Cultural Perspective. Globalization and Health, 5, 10. https://doi.org/10.1186/1744-8603-5-10

[30] Bloomfield, G.S., Kimaiyo, S., Carter, E.J., Binanay, C., Corey, G.R., Einterz, R.M., et al. (2011) Chronic Non-Communicable Cardiovascular and Pulmonary Disease in Sub-Saharan Africa: An Academic Model for Countering the Epidemic. American Heart Journal, 161, 842-847. https://doi.org/10.1016/j.ahj.2010.12.020

[31] Steyn, K., Sliwa, K., Hawken, S., Commerford, P., Onen, C., Damasceno, A., et al. (2005) Risk Factors Associated with Myocardial Infarction in Africa: The Interheart Africa Study. Circulation, 112, 3554-3561. https://doi.org/10.1161/CIRCULATIONAHA.105.563452

[32] Adedapo, A.D. (2017) Rising Trend of Cardiovascular Diseases among South-Western Nigerian Female Patients. Nigerian Journal of Cardiology, 14, 71. https://doi.org/10.4103/njc.njc_23_17

[33] Obiorah, C.C. and Amakiri, C.N. (2013) Review of Population Based Coroners Autopsy Findings in Rivers State of Nigeria. Forensic Science International, 233, 1-6. https://doi.org/10.1016/j.forsciint.2013.08.008

[34] Obiorah, C.C. and Amakiri, C.N. (2014) Autopsy Study of Traumatic/Violent Deaths in Rivers State of Nigeria. Port Harcourt Medical Journal, 8, 40-49.

[35] Galiuto, L. and Locorotondo, G. (2017) Gender Differences in Cardiovascular Disease. In: Fioranelli, M., Ed., Integrative Cardiology, Springer, Cham, 109-120. https://doi.org/10.1007/978-3-319-40010-5_9

[36] Ornstein, S.M., Nietert, P.J. and Dickerson, L.M. (2004) Hypertension Management and Control in Primary Care: A Study of 20 Practices in 14 States. Pharmacotherapy. The Journal of Human Pharmacology and Drug Therapy, 24, 500-507. https://doi.org/10.1592/phco.24.5.500.33359

[37] Ong, K.L., Tso, A.W., Lam, K.S. and Cheung, B.M. (2008) Gender Difference in Blood Pressure Control and Cardiovascular Risk Factors in Americans with Diagnosed Hypertension. Hypertension, 51, 1142-1148. https://doi.org/10.1161/HYPERTENSIONAHA.107.105205

[38] Mikkola, T.S., Gissler, M., Merikukka, M., Tuomikoski, P. and Ylikorkala, O. (2013) Sex Differences in Age-Related Cardiovascular Mortality. PLoS ONE, 8, e63347. https://doi.org/10.1371/journal.pone.0063347

[39] CDC. (2018) Men and Heart Disease Fact Sheet. Centre for Disease Control and Prevention.

[40] Akarolo-Anthony, S.N., Willett, W.C., Spiegelman, D. and Adebamowo, C.A. (2014) Obesity Epidemic Has Emerged among Nigerians. BMC Public Health, 14, 455. https://doi.org/10.1186/1471-2458-14-455

[41] Arodiwe, E.B., Nwokediuko, S.C. and Ike, S.O. (2014) Medical Causes of Death in a Teaching Hospital in South-Eastern Nigeria: A 16 Year Review. Nigerian Journal of Clinical Practice, 17, 711-716. https://doi.org/10.4103/1119-3077.144383

[42] American Heart Association (2017) Cardiovascular Disease: A Costly Burden for America Projections through 2035.

[43] Uwanuruochi, K., Odigwe, C., Chuku, A. and Oghale, O. (2015) Review of 5 Year Mortality Trend at Federal Medical Center, Umuahia Nigeria Using the Global Burden of Disease Classification. Journal of Medicine in the Tropics, 17, 60. https://doi.org/10.4103/2276-7096.162272

[44] Nwaneli, C.U. (2010) Changing Trend in Coronary Heart Disease in Nigeria. Afrimedic Journal, 1, 1-4. 